\title{
EVALUASI PROGRAM AIR SIAP MINUM DI KAWASAN MASYARAKAT MANDIRI \\ (Aplikasi Program Arsinum di Pesantren Darunajah Indramayu Jawa Barat)
}

\author{
Robertus Haryoto Indriatmoko \\ Pusat Teknologi Lingkungan, BPPT, Kawasan Puspiptek, Tangerang Selatan, 15314, Indonesia \\ Email:robertus.haryoto@bppt.go.id
}

\begin{abstract}
ABSTRAK
Memproduksi air siap minum menjadi bagian penting bagi kehidupan bermasyarakat yaitu sebuah proses untuk menyediakan sarana fasilitas yang ada untuk memenuhi kebutuhan pokok bagi masyarakat. Ini sekaligus menjadi sarana yang penting untuk keberadaan dan fungsinya dalam masyarakat. Untuk menunjang keberhasilan program tersebut, maka sarana yang ada tersebut harus dipelihara dan dimiliki sebagai sarana yang unggul dan sebagai nilai tambah yang dapat diandalkan, berdaya saing, dan tempat belajar, mengajar untuk berkembang. Untuk itu maka filosofi kehadiran sarana itu harus dapat dimengerti, termasuk sistem kinerjanya agar masyarakat dimana sarana itu berada dapat menguasai, memperbaiki sendiri jika terjadi unjuk kinerja alat yang turun sehingga dapat ditingkatkan menjadi lebih baik. Metodologi untuk menguasai keberadaan sarana tersebut dilakukan dengan terlibat langsung melalui pendidikan dan pelatihan serta ikut berpartisipasi dalam, menginstslasi sistem, agar dapat dicapai transfer of thecnology terhadap sistem kerja alat, sehingga dapat dicapai tujuan yang diinginkan serta mempraktekkannya dalam kegiatan berbisnis. Hasil dari keberadaan sarana yang ada ini menguntungkan dari sisi keuangan dan keuntungan sebagai cara untuk berkembang, tumbuh dan menjadi besar. Evaluasi dari langkah ini perlu dilakukan untuk mencapai harapan tersebut.
\end{abstract}

Kata Kunci : Minum, Fasilitas, Penting, Sukses, Transfer Teknologi, aplikasi, air siap minum

\section{EVALUATION OF READY-TO-DRINK WATER IN INDEPENDENT COMMUNITY AREA (Ready-to-Drink Water Program In Pesantren Darunajah Indramayu West Java)}

\author{
Robertus Haryoto Indriatmoko \\ Center for Environmental Technology, BPPT, Puspiptek Area, South Tangerang, 15314, Indonesia \\ Email: robertus.haryoto@bppt.go.id
}

\begin{abstract}
Producing ready-to-drink water is an important part of community life, which is a process of providing existing facilities to meet basic needs for the community. At the same time it becomes an important tool for its existence and function in society. To support the success of the program, the existing facilities must be maintained and owned as superior facilities and as an added value that can be relied on, competitive, and a place for learning and teaching to develop. For this reason, the philosophy of the presence of the facility must be understood, including its performance system so that the community where the facility is located can master, improve itself if there is a performance performance tool that goes down so it can be improved for the better. The methodology for mastering the existence of these facilities is carried out by being directly involved through education and training as well as participating in, installing the system, so that the transfer of technology can be achieved to the working system of the tool, so that the desired objectives and practices can be achieved in business activities. The results of the existence of these facilities are financially beneficial and profitable as a way to develop, grow and grow. An evaluation of this step needs to be done to achieve these expectations.
\end{abstract}

Keyword: Drinking, Facilities, Important, Success, Transfer of technology, Applied, Ready to drink 


\section{PENDAHULUAN}

Memiliki sarana air siap minum sendiri di dalam sekolah saat ini, merupakan kelebihan yang dapat digunakan sebagai nilai tambah dan keuntungan dari sisi ekonomi. Sebagai nilai tambah berarti punya keunggulan sarana sebagai ajang pembelajaran dalam bidang ketrampilan dan sarana untuk kebutuhan seharihari dan dari sisi ekonomi dapat digunakan untuk meningkatkan penghasilan atau nilai tambah yang dapat digunakan sebagai sarana pembelajaran dalam dalam bidang ekonomi (Amin Wijaya Tunggal, 2001).

Air minum menjadi bagian penting dalam kehidupan bermasyarakat sebagai sarana fasilitas atau sarana yang ada untuk memenuhi kebutuhan hidup Masyarakat. Ini sekaligus menjadi sarana yang penting bagi keberadaan dan fungsinya dalam masyarakat (Haryoto Indriatmoko, R dan Widayat W, 2007). Untuk menunjang keberhasilan program tersebut, maka sarana yang ada tersebut harus dikuasai secara sistem pengolahan, dipelihara dan dimiliki sebagai sarana yang unggul sebagai nilai tambah yang dapat diandalkan, berdaya saing, sebagai tempat belajar dan mengajar dan nantinya layak untuk dikembangkan di tempat lain.

Untuk hal tersebut maka filosofi bagi kehadiran sarana itu harus dapat dipahami oleh setiap pengurus atau sistem kinerjanya dapat dipahami dengan baik oleh pihak manajemen dimana sarana itu berada, dapat dikuasai, dan diperbaiki sendiri jika terjadi kerusakan, dan produknya dapat dapat tetap terjaga.

Metodologi untuk menguasai sarana tersebut dilakukan melaui pendidikan dan pelatihan ikut berpartisipasi pada saat menginstslasi, melalui transfer of technology untuk tujuan yang diinginkan. Dengan semakin mengenal teknologi maka peningkatan akan ilmu pengetahuan teknologi dan kesehatan akan semakin meningkat.

Hasil produksi dari keberadaan sarana dan prasarana tersebut akan terasa fungsinya, cocok untuk masyarakat. Salah satu contoh dari kegiatan tersebut adalah keberadaan sarana pengolahan air siap minum di masyarakat sekolah.

Keberadaan sarana tersebut akan menjadi kebutuhan yang sangat penting untuk masyarakat sebagai sarana dasar untuk menunjang kebutuhan harian. Dimana kebiasaan minum air yang memenuhi syarat kesehatan menjadi kebiasaan yang menyehatkan. Minum air siap minum yang bersih dan sehat menjadi kebiasaan yang baik untuk dibiasakan.

Sangat penting bagi pengurus yang akan mengoperasikan alat pengolah air siap minum untuk menguasai keberadaan alat tersebut yang bukan hanya dapat memberikan nilai keuntungan dari sisi ekonomi akan tetapi dapat memberikan keuntungan terhadap nilai kesehatan maka semangat untuk bisa memproduksi yang mempunyai nilai ganda maka juga akan meningkatkan hasil produksi.

Untuk hal tersebut maka prosedur standar operasi alat harus benar agar dapat dicapai dan menghasilkan produksi yang baik dan benar maka kedua keuntungan tersebut harus dapat tercapai. Kebiasaan mengoperasionalkan alat secara benar harus dilakukan dengan benar dan pembagian tugas antar pengurus harus dilakukan secara benar agar produk yang dihasilkan dapat laku dipasanan.

Peranan pelatihan untuk tingkat penyelenggara arsinum, pengoperasian alat atau sistem pengolahan menjadi prosedur yang standar. Untuk tingkat manajerial dan kepada calon operator, perlu dibekali pelatihan yang memadahi dengan satu pengertian mulai dari penetapan air sebagai bahan baku sampai dengan produk yang bermutu dengan hasil yang berupa air siap minum yang berkualitas berupa air yang siap minum, jernih, bersih, siap dikonsumsi dan telah diteliti di laboratorium yang kompeten.

\subsection{Ruang Lingkup}

Pesantren Darunajah merupakan sebuah pusat pendidikan yang bergerak dalam bidang Agama dan pusat ketrampilan bagi masyarakat sekolah. Di Pesantren ini dilakukan kegiatan ketrampilan berupa pendidikan keagamaan mulai dari kegiatan membaca sampai saritilawal sampai mengkaji ilmu agama Islam dan pendidikan umum, konseling serta ilmu modern termasuk didalamnya bagaimana peran teknologi terutama yang berkaitan dengan pengolahan air.

Kegiatan yang saat ini sedang dirintis munculah ide untuk menyurati BPPT. Sebagai jawaban atas permintaan tersebut maka dibuatlah kerjasama untuk pengadaan alat tersebut sehingga akhinya kerja sama tertsebut dapat dilaksanakan dan dilaksanakanlah. Oleh adanya kegiatan yang bersifat kemasyarakanan dan sosialisasi maka berdasarkan anggaran yang ada dilakukanlah sosialisasi program kepesantran yang bersangkutan dan pada bulan Juni 2018 dilakukan kunjungan tim BPP Teknologi ke Pesantren Darunajah Indramayu Jawa Barat.

Pada bulan itu dilakukan kunjungan dan survai awal untuk mengetahui asaL sumber air, jarak dan sumberdaya listrik yang dibutuhkan. Berdasarkan hasil survai ada dua sumber air yaitu: 1. Berasal dari empang dan 2. Berasal dari PDAM yang masuk ke daerah itu. Sumberair yang berasal dari empang hanya tersedia pada bulan basah dan pada bulan kemarau airnya kering. 
Juga pada bulan basah air empang tersebut berbau, terbuka dan keruh sekali dan terletak jauh dari tempat pengolahan. Sumber air yang berasal dari PDAM jumlah airnya sedikit, keruh dan berwarna agak cokelat.

Akhirnya pilihan terletak pada sumber air baku yang berasal dari PDAM karena dengan pertimbangan bahwa ketersediaan pada segala musim tersedia dengan baik dan hanya masalah suplai yang kurang banyak itu bias diatasi dengan meningkatkan atau memperbesar kapasitas langganan sehingga dari sisi kuantitas dapat ditingkatkan.

Dalam survai awal tersebut juga dilakukan kegiatan pemilihan lokasi pengolahan. Oleh pak ketua Pesantren K.H Asror Shobari lokasi pengolahan ditetapkan jadi satu dengan Masjid, dengan harapan akan mejadi ikon depan dan modern, selain itu ada air bersih menjadi air siap minum dari pengolahan yang air bersih sekaligus untuk tambahan air wudlu yang bersih bagi jamaah yang mau sholat.

Setelah dilakukan survai mengenai Sumberdaya, Jumlah user dan penyiapan tenaga operator yang terdiri dari teknisi, operator manajemen dan tenaga pemasaran yang merupakan ujung tombak dari kagiatan ini. Seorang teknisi diwajibkan punya ketrampilan teknis, listrik dan mesin sedangkan seorang manajerial harus punya jiwa bisnis dan ekonomi. Sedangkan seorang pemasaran harus punya jiwa menjual, dan melayani pembeli. Jika pengetahuan dan kemampuan tersebut dimiliki oleh ke tiga ujung tombak tersebut maka usaha yang dilakukan akan berhasil di lakukan dengan baik.

Selanjutnya tim survai memberikan hasil yang diperoleh dan dilaporkan ke kantor pusat untuk dilakukan koordinasi dan rencana disain untuk melakukan kegiatan tersebut di lapangan nantinya. Tim yang dibentuk akan dibagi dua yaitu tim Teknis dan non Teknis.

\subsection{Tujuan}

Tujuan diterapkannya system ini di Sekolah adalah untuk:

1. Pengematan biaya untuk keperluan masak air

2. Pemenuhan kebutuhan hidup akan air minum.

3. Peningkatan Ekonomi sekolah dan Nilai tambah. daya saing Sekolah.

4. Sarana transfer pengetahuan dan teknologi

5. Sarana ajang pendidikan (Belajar teknologi, Ekonomi dan Kesehatan).

\section{METODOLOGI}

Untuk keberhasilan penerapan teknologi ini maka teknik penerapannya dilakukan dalam dua tahap yaitu: Secara Teknis dan Non Teknis.
Secara Teknis berupa Bahan dan Alat yang mendukung diterapkannya keberadaan alat tersebut. Bagaimana disain teknis dan Lay out dari kinerja sistem tesebut, hal itu yang dibahas oleh tim teknis. Ini dimulai dari pembuatan gambar untuk rencana disain dan lay out, disain dalam bentuk setengah jadi dalam kit yang tinggal sambung untuk memudahkan pengiriman dan pembelajaran serta sistem serta teknisi yang bertugas untuk merakit dilapangan nantinya.

Untuk tim non teknis yang dikerjakan adalah bagaimana system pengolahan, produksi atau hasil itu sampai di pasar atau ke tangan user. Tim non teknis juga harus memastikan produk itu laku dipasaran, aman dan nyaman, oleh kasena itu tim teknis juga perlu membekali operator, manajerial sampai teknisi pengetahuan yang cukup untuk bekal mereka. Untuk itu dalam metodologi tersebut peran antar tim teknis dan nan teknis harus berjalan saling mengisi. Bekal-bekal yang harus dipersiapkan dilapangan sebagai bahan didik bagi pengelola.

Untuk menunjang hasil produksi yang sehat maka secara kualitatif juga harus ditunjang dengan hasil laboratorium yang bonafide supaya hasil yang diproduksi dapat dipertanggung jawabkan secara hukum. Data hasil pengecekan produksi harus diketahui olek masyarakat untuk menunjukkan bukti bahwa air siap minum yang dikonsumsi benar-benar sehat dan baik untuk tubuh.

\section{HASIL DAN PEMBAHASAN}

Pembahasan atas hasil dari kegiatan ini akan dipusatkan pada hasil kegiatan yang dibagi dalam 2 kegiatan yaitu aspek teknis dan non teknis. Ini dimaksudkan agar hasil kegiatan ini tidak menjadi pilot proyek yang mangkrak akan tetapi dapat menghasilkan pilot proyek yang nyata dan berkembang di masyarakat.

\subsection{Pelajaran Dari Aspek Teknis}

Secara teknis system pengolahan air siapminum ini dirancang seperti Gambar 1 yaitu:

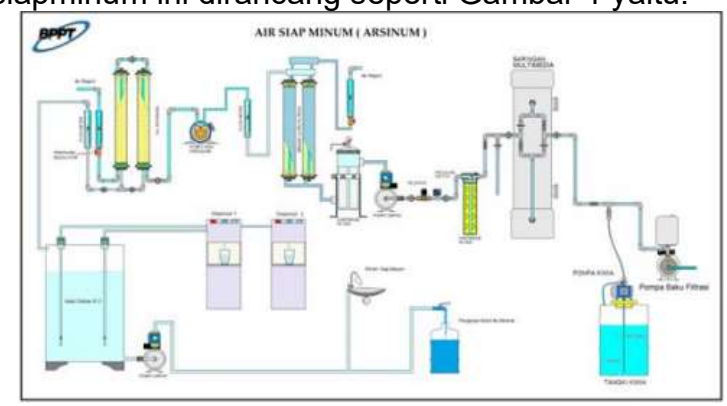

Gambar 1. Rangkaian Sistem Pengolahan Air

Siap Minum di Sekolah Pesantren ASSARIAH di desa Krukut, Indramayu Jawa Barat. 
Sistem kelistrikan dalam gambar tersebut dibagi dalam 2 kontrol panel yaitu kontrol panel yang bekerja untuk mengontrol bagian pengolah awal yang digunakan untuk mengontrol penyaring tingkat awal dan control panel yang digunakan untuk mengontrol system ultra filtrasi, system reverse osmosis atau $\mathrm{RO}$, mengontroler pressure valve, mengontrol otomatik level, mengontrol ultra violet dan power supply untuk tampilan system $L C D$.

Kontrol panel awal cara bekerjanya adalah untuk memberi tegangan atau power supply pompa air baku supaya bekerja dan menyalakan pompa dosing. Jika level air baku mencukupi maka pompa air baku akan bekerja dengan cara memompa air baku dan menginjeksi oksidator untuk zat besi dan mangan yang terlarut dalam air baku. Kemudian air baku yang sudah teroksidasi ini dapat disaring dengan filter multimedia sehingga air produk dapat tersaring dan dapat menghasilkan air bersih, bening sudah tersaring zat besi dan mangan yang terkandung dalam air baku. Air bersih ini siap diumpankan ke pengolah tingkat selanjutnya yaitu filter ultra filtrasi.

Tekanan air agar diolah ke penyaring ultra filtrasi ini dengan debit sebesar $>35$ liter/menit dengan tekanan air kira-kira 2-5 bar. Syarat tekanan air ini akan menghidupkan panel kontrol ke dua. Air bersih sebesar 21 liter per menit dan sisanya berupa air reject sebesar 20 liter/menit, karena kita mengelola air bersih dari ultra filtrasi sebesar 50 \%nya.

Air dengan debit dan tekanan diatas 2 bar ini akan dapat menghidupkan penyaring ke dua yaitu ultra filtrasi. Penyaring ini dapat menyaring kekeruhan antara 0,1-0,01 mikron namun untuk lebih amannya penyaring ultra filtrasi ini dilindungi oleh bag filter atau kantong filter.

Ketika panel kontrol ke dua hidup atau on maka itu berarti sudah ada arus listrik yang akan siap untuk memggerakkan pompa tekanan tinggi, namun panel kontrol Ini juga juga akan bekerja kalai tekanan pompa dari ultra filtrasi yang akan masuk ke panel kontrol mencapai tekanan minimal 2 bar dan tekanan maximal dari pompa tekanan tinggi yang akan menekan membrane reserve osmosis (RO) maximum adalah $>15$ bar. Jika hal itu terpenuhi maka pompa tekanan tinggi akan bekerja, menekan membrane RO sehingga membrane $\mathrm{RO}$ akan menghasilkan produksi dari RO menghasilkan air bersih dengan kapasitas produksi sebesar $>15 \mathrm{l} /$ menit dan air reject $\mathrm{RO}$ kira kira 5 liter per menit. Perbandingan operasi untuk menghasilkan air bersih dengan perbandingan 70: 30 persen.

Sistem kelistrikan secara lengkap dapat dilihat pada Gambar 2.

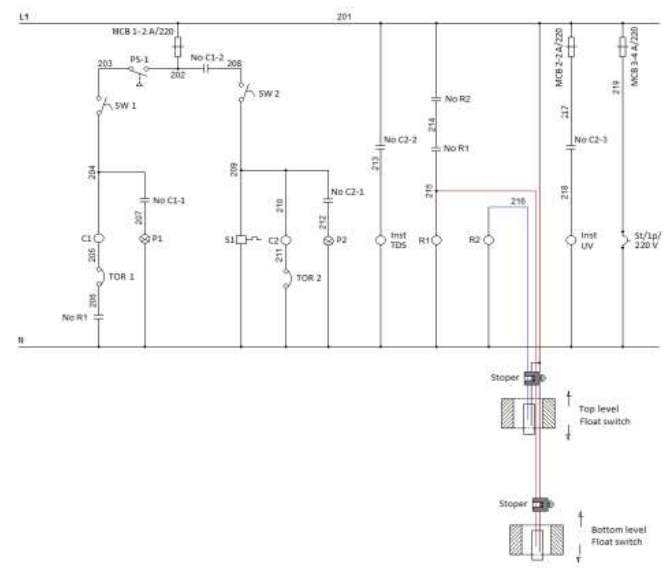

Gambar 2. Sistem kelistrikan Untuk Kontrol Panel ultra Filtrasi dan RO

Jika hasil produksi yang sudah tertampung di tangki produksi sudah mencapai lever tertentu (Maximal) maka kontrol panel ke dua ini akan secara automatis mati. Hal ini dapat bekerja jika level air yang di produksi RO sedah mencapai level yang diinginkan. Untuk level batas minimal akan on sedang pada level batas maksimal akan off secara automatic.

Alat pengolah air siap minum ini sudah dilengkapi dengan penambah $\mathrm{pH}$ air berupa alat korosex (magnesium oksida). Yang akan dibahas di bawah ini:

Sebagai gambaran secara umum sistem pengolahan air siap minum ini dibangun atas 4 sistem yaitu:

1. Pengolah tingkat awal yang memiliki peralatan terdiri dari system control yang berguna untuk mengontrol air baku, sistem oksodasi basi, mangan dan kekeruhan. Air baku yang msih mengandung kelarutan besi dan mangan dioksidasi dengan $\mathrm{KMnO} 4$ atau kalium permanganate agar zat besi dan mangan dapat diendapkan dan disaring menggunakan filter sand, mangan zeolite dan carbonactive agar dapat dikurangi kadarnya dalam air baku sehingga sesuai dengan kriteria desain dari air baku agar kadar besi dan mangan ada dibawah 0,1 ppm dan air baku menjadi bersih, tidak berwarna dan tidak berbahu.

2. Pada tahap ke dua pengolahan didesain dengan menggunakan alat ultrafiltrasi. Yaitu menggunalan filter ultrafiltrasi sebagai alatnya. Tekanan operasi alat adalah maximum dengan 2 bar. Debit yang dihasilkan oleh ultra filtrasi ini minimal sama dengan debit yang dihasilkan untuk mensuplay debit RO. Kekurangan jumlah debit untuk memproduksi RO dapat menyebabkan kerusakan yang dimulai dengan kavitasi debit antara ultra filtrasi dan 
pompa RO. Akan berpengaruh pada jumlah air siap minum yang akan dihasilkan. Tekanan naik air pada ultra filtrasi dan debit $R O$ berkurang. Pengolahan dengan menggunakan ultra filtrasin akan menghasilkan air bersih dengan tingkat penyaringan dengan kekeruhan ada dibawah 0,01 mikron. Air bersih yang dihasilkan sangat bagus sebagai input dari sistem $R O$.

3. Tahap ke tiga yaitu penyaringan pada tingkat membran semipermeable yaitu tingkat $R O$. Alat yang penting disini adalah pengatur tekanan masuk untuk $R O$ dan keluar $R O$ alat ini mengontrol pompa tekanan tinggi jika tekanan operasi kurang dari 10 bar maka pompa tidak hidup dan jika tekanan lebih dari pompa tekanan tinggi $R O$ misalnya max 15 bar pompa juga tidak akan hidup. Produk yang dihasilkan dari system ini adalah air siap minum dengan tingkat filtrasil 0,001 mikron, steril, TDS rendah, dengan $p H$ asam biasanya $\mathrm{pH} 5$ dan ini akan dinaikkan sampai pH 6 sampai 7 dengan penambahan mineral misal korosex (Magnesium oxide) sehingga layak minum.

4. Tahap keempat yaitu merupakan tahap penampungan dan tahap produksi dimana sistem pengolahan ditambahkan tempat untuk memproduksi air hasil pengolahan tahap ketiga dan alat untuk mendistribusikan hasil pengolahan kepada masyarakat atau user. Sterilisasi hasil produksi dijaga dengan pemasangan lampu ultra violet. Lampu ini dasamping sebagai sterilisator tabung juga berguna untuk sterilisator hasil produksi atau penampungan di botol galon, supaya hasil produksinya tetap terjaga dari pencemaran dan tidak berbau.

Keempat tahap tersebut merupakan tahap penting dalam produksi, agar diperoleh hasil yang optimal dalam proses produksi. Selanjutnya ada tahap yang juga penting untuk di lakukan agar distribusi hasil dapar dinikmati user adalah tahap pemasaran. Tahap ini dimulai dari bagaimana mengenal user secara lebih baik. Hal yang penting dilakukan di tahap ini adalah:

1. Menjaga kualitas produksi. Artinya adalah hasil produksi yang terjaga, mutu, atau kualitas produksi, dan kebersihan, aman dan nyaman. SOP yang baku.

2. Melayani pasar yaitu: selalu ada di pasaran meskipun jumlah produksinya terbatas jangan sampai ada stroke/Catatan yang kosong. Syukur-syukur sebagai pengusaha mau menjemput bola, dengan mengisi kelangkaan air siap minum yang ada pada masyarakat yang membutuhkan.

3. Menjaga kebersihan lokasi, Ini dilakukan untuk menunjukkan kepada bahwa hasil produksi yang dihasilkan tercermin dari kebersihan lingkungan disekitarnya.

4. Frekuensi dilakukannya tahap 1-3 ini juga sangat penting dilakukan, hal ini dilakukan sebagai komitmen perusahaan, berapa kali jumlah yang dilakukan untuk pemeriksaan air baku, arsinum hasil produksi dan kebersihan lingkungan

Hasil analisis terhadap produksi pengolahan menggunakan air baku yang berasal dari air tanah dari lokasi terpasang telah dimanfaatkan menjadi air siap minum.

\subsection{Pelajaran Dari Aspek Non-Teknis}

Untuk menjadi seorang manajer beserta jajarannya yang handal dan tangguh maka aspek non teknis haruslah menguasai unjuk kerja dari sistem ini secara matang. Kinerja dari sistem yang dibangun ini terdiri dari cara teknik berproduksi, cara sampling dan menunggu hasil uji di laborstorium, kenerja atas hasil uji dan teknik pemasaran (jemput bola)/pelayanan.

Ada 4 tahap yg harus diketahui oleh seorang manajer dasn berkaitan dengan operasional system yaitu:

1. Mempersiapkan Air Baku: Mencuci multi media (Untuk media baru dan lama (penggantian). Filter macro multy media sebelum digunakan sebaiknya dicuci terlebih dahulu. Cara mencuci pada tahap pertama adalah merendan multy media terlebih dahulu dengan cara mengisi dan merendan media filter dengan air baku supaya bahan pengfotor yang melekat dalam multi media terlepas dari media filter. Ingat pada saat merendam dan mencuci multy media filter valve ke pengolah selanjutnya harus dalam keadaan tertutup. Aliran baik cuci maupun bilas hanya keluar melalui saluran pembuangan, Sampai hasil pencucian dikaakan bersih. Kemudian valve pembuangan ditutup dan valve kearah pengolahan berukutnya dibuang. Cara penyaringan biasakan dengan sistem up flow filter sedangkan cara mencuci dengan system down flow filter.

2. Pada waktu tekanan dari pompa mencapai lebih dari 2 bar maka panel kontrol ke dua dalam keadaan on. Sehingga dapat dikatakan ada tegangan listrik yang kerja dan pompa tekanan tinggi menyala. Atur rejeck ultra filtrasi dan produksi 50\%:50\% dengan cara memutar regulator ultra filtrasi, sampai debit produksi mencapai $21 \mathrm{l} /$ menit dan tekanan air output dari ultra filtrasi mencapai max 2 bar lebih sedikit maka panel kontrol sudah on.

3. Mengatur regulator valve sehingga $60 \%$ dibanding $40 \%$ antara air rejeck dengan air 
siap minum produksi RO menggunakan parameter tekanan regulator mulai dari tekanan input 2 bar sampai produksi 15 bar dan debit produksi mencapai 12,6-15 liter per menit yang dihasilkan oleh membrane RO. Dengan hasil air reject $\mathrm{RO}$ mencapai 7,8 - 5 liter/menit. Maka untuk jumlah produksi air RO atau air siap minum sebesar 15 liter per menit.

4. Air hasil produksi siap minum kemudian di simpan dalam tangki produksi air siap minum. Usahakan hasil produksi tersebut sudah di periksakan di laboratorium yang kompeten. Jlka hasilnya layak dan direkomendasikan menjadii air siap minum. Setelah semuanya beroperasi maka harus dipersiapkan sampling air siapm minum untuk menjaga kualitas produksi sebagai air siap minum. Pengambilan sampel air siap minum untuk diperiksa ke laboratorium sebaiknya dapat dilakukan setiap bulan sekali.

Tugas dan kewajiban yang harus dilakukan untuk seorang teknisi:

1. Seorang teknisi atau operator harus harus hapal atau terlatih dengan 4 prosedur operasi menjalankan sistem pengolahan air siap minum dengan baik.

2. Mencatat log book dengan tepat waktu, tepat sasaran dan tepat fungsi akan mengurangi kerusakan dan meningkatkan efisiensi, data log book ini harus selalu dianalisis oleh petugas yang kompeten.

3. Menguasai teknis termasuk teknis mengoperasikan sistem yang berwawasan lingkungan.

4. Mempunyai jadwal pemeriksaan kualitas air hasil produksi dengan laboratorium.

5. Berupaya meningkatkan mutu atas segala keluhan yang timbul atau muncul (berikan no telepon pengaduan).

6. Berupaya melakukan kontak dengan ahli (BPP Teknologi) untuk menjaga sistem dan kualitas produksi.

7. Menjaga kebersihan botol/sterilisasi terutama yang akan diisi ulang dengan cara mencuci/strerilisasi terlebih dahulu.

8. Menyegel dan menjaga hasil produksi, salah satu cara yang dilakukan adalah menjaga hasil produksi terhadap sinar matahari secara langsung.

Seorang petugas administrasi dan pemasaran sebaiknya melakukan tugas sebagai berikut:

1. Melakukan pencatatan jumlah gallon yang keluar.

2. Melakukan perhitungan keuangan.

3. Mengumumkan hasil laboratorium.
4. Membuka telepon pemesanan

5. Memberikan kontak person komplain kepada Teknisi untuk perbaikan.

6. Memastikan produksi yang baik, cukup dan tersedia di pasaran.

7. Menjaga ketersediaan produksi di pasaran, agar tidak terjadi kalangkaan.

8. Memberikan jadual kepada diri sendiri/manajer, bagian teknisi, pemasaran dan produksi.

9. Mengingatkan agar selalu melakukan "Standar Prosedur Operasi" secara rutin dan benar.

\section{KESIMPULAN DAN SARAN}

Berdasarkan ervaluasi kegiatan dan sosialisasi program air siap minum ini, maka dapat ditarik kesimpulan:

1. Program ini dapat dipakai sebagai acuan untuk pengelolaan arsinum secara keseluruhan/umum.

2. Jumlah produksi yang besar, cepat serta hemat bahan bakar karena menggunakan energy listrik.

3. Jika produksi dijalankan dengan baik maka hal ini dapat dipakai untuk menyelesaikan hasil yang lebih besar. Sehingga ada satu harapan untuk mengembangkan bisnis ini menjadi lebih besar.

4. Konsumen akan merasa puas terutama jika produk ini bermutu, terjaga kebersihannya, tepat rasa, dan ketersediaan produksi ada atau selalu tersedia di pasaran.

5. Jika prosedur yang ditetapkan ini bisa dijalankan dengan baik, kemungkinan akan meningkatkan hasil produksi, meningkatkan produksi jadi lebih dapat memperluas pasar.

6. Memiliki rasa tanggung jawab besar terhadap masing-masing petugas, mulai dari tingkat manajer, pelaksana lapangan, termasuk pemasaran dan teknisi maka tugas yang lebih besar akan bias diselesaikan dengan baik.

\section{UCAPAN TERIMA KASIH}

Khususnya kami sampaikan terima kasih yang besar kepada Direktur Pusat Teknologi Lingkungan BPP Teknologi ub. Dr. Ir. Rudi Nugroho, M. Eng, yang telah menganggarkan biaya untuk kegiatan ini, mulai dari survai awal sampai dengan acara ini diresmikan dengan baik dan juga teman-teman mulai dari para teknisi sampai dengan tim sosialisasi. Melalui program yang telah dijalankan. 


\section{DAFTAR PUSTAKA}

1. Aditya Bakti. Munawir. (1994). Akuntansi Keuangan. Liberty, Yogyakarta.

2. Amin Widjaya Tunggal. (2001). Memahami Konsep Economic Value Added (EVA) dan Value Based Management (VBM).

3. Bambang Riyanto, (1992). Dasar-Dasar Pembelajaran Perusahaan. Edisi Ketiga Salemba Empat, Jakarta.

4. Erich A, (1996). Teknik Analisis Keuangan. Edisi 8. Erlangga. Ikatan Akuntansi Indonesia. 2002. Standar Akuntansi Keuangan. Buku I. Salemba Empat, Yogyakarta:.

5. Haryoto Indriatmoko, R dan Widayat Wahyu, 2007. Penyediaan Air MInum Pada Situasi
Tanggap Darurat Bencana Alam (Belajar Dari Kasus Gempa Bumi Yogyakarta dan Jawa Tengah). Jurnal Air Indonesia, Volume 3, No. 1 Maret 2007, Hal 29-37 ISSN 0216-4140, Hal 29-37. PTL. Indonesia.

6. Harvarindo. Arsyad. (1997). Ekonomi Pembangunan. STIE YKPN, Yogyakarta:

7. Mulyadi. 1997. Akuntansi Manajemen, Konsep Manfaat dan Rekayasa. Edisi Dua. STIE YKPN. Yogyakarta:

8. Mulyadi dan Jhoni Setawan. 2001. Sistem Perencanaan Pengendalian Manajemen. Edisi I: Yogyakarta. 


\section{Lampiran}

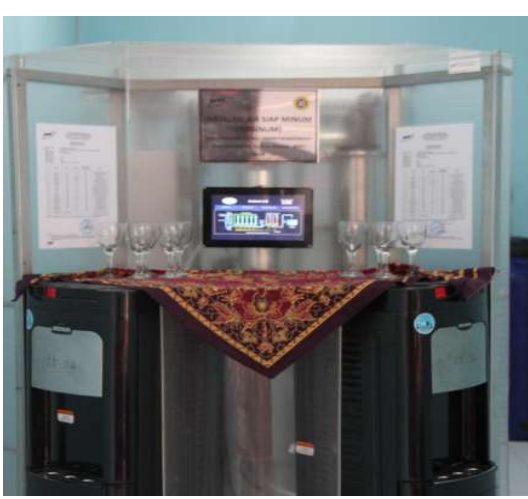

Instalasi Arsinum

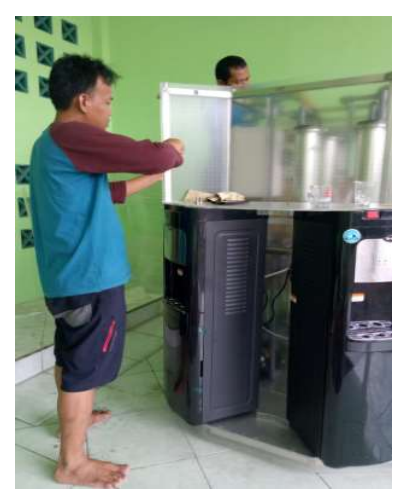

Instalasi Arsinum

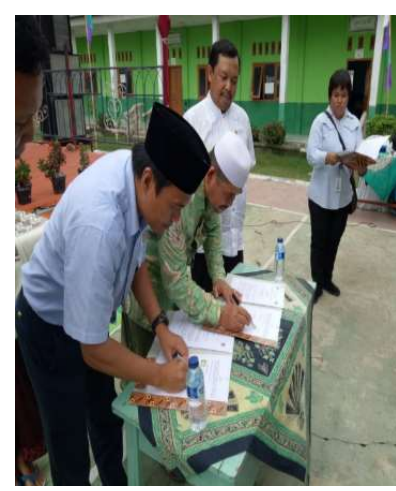

Penandatanganan Peresmian
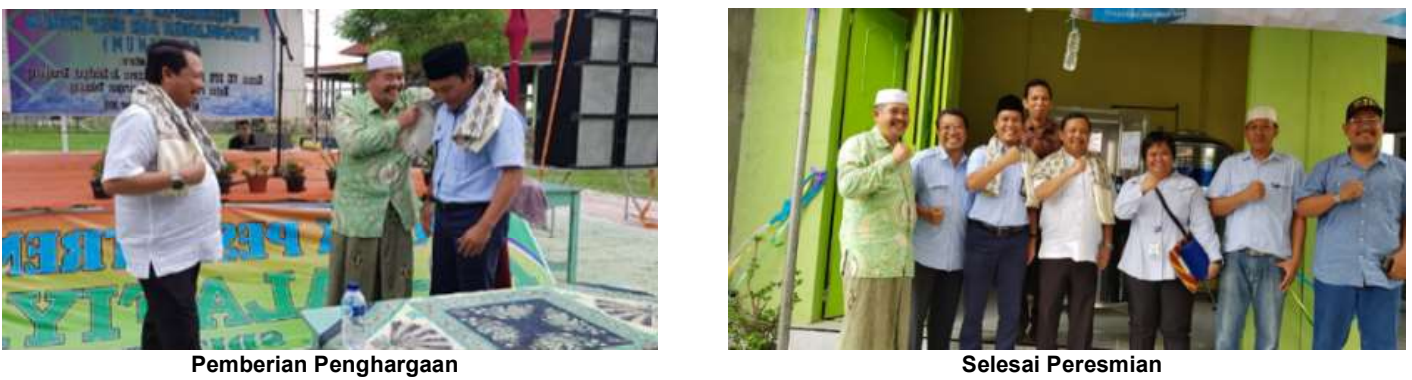